\title{
Genome-wide mapping of Polycomb target genes unravels their roles in cell fate transitions
}

\author{
Adrian P. Bracken, ${ }^{1}$ Nikolaj Dietrich, ${ }^{1}$ Diego Pasini, ${ }^{1}$ Klaus H. Hansen, ${ }^{1}$ and Kristian Helin ${ }^{1,2,3}$ \\ ${ }^{1}$ Biotech Research and Innovation Centre (BRIC), 2100 Copenhagen $\varnothing$, Denmark; ${ }^{2}$ Faculty of Health Sciences, University of \\ Copenhagen, 2200 Copenhagen N, Denmark
}

The Polycomb group (PcG) proteins form chromatin-modifying complexes that are essential for embryonic development and stem cell renewal and are commonly deregulated in cancer. Here, we identify their target genes using genome-wide location analysis in human embryonic fibroblasts. We find that

Polycomb-Repressive Complex 1 (PRC1), PRC2, and tri-methylated histone H3K27 co-occupy >1000 silenced genes with a strong functional bias for embryonic development and cell fate decisions. We functionally identify 40 genes derepressed in human embryonic fibroblasts depleted of the PRC2 components (EZH2, EED, SUZ12) and the PRC1 component, BMI-1. Interestingly, several markers of osteogenesis, adipogenesis, and chrondrogenesis are among these genes, consistent with the mesenchymal origin of fibroblasts. Using a neuronal model of differentiation, we delineate two different mechanisms for regulating PcG target genes. For genes activated during differentiation, PcGs are displaced. However, for genes repressed during differentiation, we paradoxically find that they are already bound by the PcGs in nondifferentiated cells despite being actively transcribed. Our results are consistent with the hypothesis that PcGs are part of a preprogrammed memory system established during embryogenesis marking certain key genes for repressive signals during subsequent developmental and differentiation processes.

[Keywords: Polycomb; chromatin; epigenetics; stem cells; differentiation]

Supplemental material is available at http://www.genesdev.org.

Received January 30, 2006; revised version accepted March 3, 2006.

The human body consists of at least 200 different types of cells. The response of each of these cells to extra- or intracellular signals depends on their particular lineage "identity." In other words, despite having identical genomes, cells can respond in markedly different ways to the same stimulus. Therefore, a strong "programming" system must function to preserve and specify the identity of each cell type. It has become increasingly clear in recent years that maintenance of cell identity and, to a certain extent, also specification of cell identity are controlled by epigenetic events (Fisher 2002; Jaenisch and Bird 2003; Hsieh and Gage 2004; Valk-Lingbeek et al. 2004). These epigenetic events, which include DNA methylation and post-translational modifications of the histones, control the transcriptional program of each cell by regulating chromatin structure. The histone modifications are thought to constitute an indexing mechanism, referred to as the "histone code" (Jenuwein and Allis 2001), containing information such as the past and

${ }^{3}$ Corresponding author.

E-MAIL kristian.helin@bric.dk; FAX 45-3917-9669.

Article published online ahead of print. Article and publication date are at http://www.genesdev.org/cgi/doi/10.1101/gad.381706. present gene activity and the physiological status of the cell. This code is deciphered by other protein complexes, which specifically recognize and bind the modified histones and, in turn, elicit the biological effects of the imprints. The Polycomb repressors and Trithorax activators are thought to be the central players in these epigenetic programming events (Orlando 2003; Molofsky et al. 2004; Valk-Lingbeek et al. 2004).

Polycomb group genes (PcGs) are usually considered as being transcriptional repressors that are required for maintaining the correct spatial and temporal expression of homeotic genes during development and were originally identified based on studies demonstrating that deletions of PcG genes lead to homeotic transformations of fruit flies (Orlando 2003; Ringrose and Paro 2004; Pirrotta and Gross 2005). The vertebrate homeotic HOX genes are located in four distinct clusters (A, B, C, D) that are organized into 13 homology (or paralog) groups (Pearson et al. 2005). The chromosomal organization of the genes in each $H O X$ cluster reflects its anterior-posterior expression in the body plan. The "tail" $H O X$ genes at the $5^{\prime}$ end of the HOXA locus (i.e., HOXA7-13) are expressed predominantly in the posterior of the developing embryo. In PcG knockout mice, the repression of these 
"tail" HOX genes is impaired in the middle and head part of the embryo, resulting in posterior-to-anterior transformation defects (Levine et al. 2004; Lund and van Lohuizen 2004).

Recent biochemical approaches have established that the PcG proteins form multiprotein complexes, called Polycomb-Repressive Complexes (PRCs). PRC2 contains EZH2, EED, SUZ12, and RbAp48, while the PRC1 complex consists of $>10$ subunits including the oncoprotein BMI-1 and the HPC proteins $(\mathrm{CBX} 2, \mathrm{CBX} 4, \mathrm{CBX} 7$, CBX8), HPH1-3, RING1-2, and SCML (Levine et al. 2004; N. Dietrich, K. Helin, and K.H. Hansen, unpubl.). Functionally, EZH2 is the catalytically active component of PRC2, acting as a histone methyltransferase specific for Lys 27 (K27) of histone H3 and K26 of histone H1 (Cao and Zhang 2004; Kuzmichev et al. 2004). Interestingly, the HPC proteins of the PRC1 complex can specifically bind to tri-methylated H3K27 (H3K27me3) (Cao and Zhang 2004; Kuzmichev et al. 2004; N. Dietrich, K. Helin, and K.H. Hansen, unpubl.). Since PRC2 is required for PRC1 binding to chromatin (Rastelli et al. 1993; Hernandez-Munoz et al. 2005), it has been proposed that this is primarily achieved through binding of HPC proteins to H3K27me3. Recently, the PRC1 complex has been demonstrated to possess a H2A-K119 ubiquitin E3 ligase activity that, like $\mathrm{H} 3 \mathrm{~K} 27 \mathrm{me} 3$ activity, is associated with the repression of $H O X$ genes (Cao et al. 2005).

In addition to being essential regulators of embryonic development, the PcGs have also emerged as key players in the maintenance of the adult stem cell populations (Molofsky et al. 2004; Valk-Lingbeek et al. 2004). For example, BMI-1 is required for the self-renewal of hematopoietic and neural stem cells (Lessard and Sauvageau 2003; Molofsky et al. 2003), while overexpression of EZH2 is capable of blocking the differentiation of muscle myoblasts (Caretti et al. 2004) and preventing hematopoietic stem cell exhaustion (Kamminga et al. 2005). Consistent with their critical roles in development, differentiation, and stem cell renewal, several PcGs are oncogenes, overexpressed in both solid and hematopoietic cancers (Pasini et al. 2004a; Valk-Lingbeek et al. 2004; Raaphorst 2005).

Although substantial progress has been made toward understanding the biological and biochemical functions of PcG proteins, we still know little about how precisely they control development and cell fate decisions. Since it is believed that they primarily function as epigenetic regulators of transcription, we performed chromatin immunoprecipitations (ChIP) and genome-wide screenings using tiled arrays to identify PcG target genes in human cells. Strikingly, we observe a very strong bias for genes controlling development and cell fate decisions. We investigate the functional relevance of PcG regulation in both human embryonic fibroblasts and in a model of neuronal differentiation. Moreover, we show that the PcGs target several tumor suppressor genes and genes known to be down-regulated in cancer. Based on these data, we propose models for how the PcGs control transcription.

\section{Results \\ Identification of gene expression changes in cells depleted of PRC1 and PRC2 members}

To obtain an understanding of how the PcGs control development and cell fate decisions, we chose to identify their target genes. To do this, we wanted to perform ChIP experiments using specific PcG antibodies followed by probing of microarrays (chips) with the enriched material (ChIP-on-chip). As an initial screen, we identified candidate genes by performing expression array analysis of PcG-depleted cells. Then subsequently, by generating tiled arrays mapping the complete loci of these potential target genes and probing with the enriched material, we aimed to identify functionally relevant direct targets.

We transfected proliferating human embryonic diploid fibroblasts (TIG3) with small interfering RNA (siRNA) oligonucleotides specific for the PRC2 components (EZH2, EED, and SUZ12) or the PRC1 component BMI-1. Western blot analysis of lysates prepared $44 \mathrm{~h}$ after transfection confirmed that the siRNAs efficiently inhibited the protein synthesis of their specific targets (Fig. 1A). As described previously, the protein levels of PRC2 members are in part dependent on the presence of the other partners in the complex (Pasini et al. 2004b). RNA was extracted at this point and labeled and hybridized to Affymetrix gene expression arrays (HG-U133). The short incubation period with siRNA oligonucleotides generated small but reproducible expression changes in several hundred genes. We observed a substantial overlap in gene expression changes after inhibiting the expression of BMI-1 and the three proteins of the PRC2 complex (Fig. 1B). In order not to miss any relevant genes for the subsequent ChIP-on-chip analysis, we selected a total of 341 genes as potential PcG target genes, whose expression is significantly changed upon down-regulation of at least three out of the four PcG proteins analyzed in our experiments (Fig. 1C; Supplementary Table 1). The reliability of the expression array data was confirmed by performing quantitative real-time PCR analysis (qPCR) of a selection of 18 genes (Fig. 1D; data not shown).

PcG binding and overlapping H3K27 tri-methylation of complete gene loci in the HOX gene clusters

To identify target genes by ChIP analysis, we first screened several candidate antibodies specific for PRC1 and PRC2 proteins and the tri-methylated $\mathrm{H} 3 \mathrm{~K} 27$ for their ability to efficiently coimmunoprecipitate histone $\mathrm{H} 3$ in ChIP conditions (data not shown). From this analysis we selected antibodies specific for SUZ12 (PRC2), CBX8 (PRC1), and H3K27me3. To validate the specificity of these antibodies in the ChIP-on-chip analysis, we represented the entire $\operatorname{HOX} A, \operatorname{HOXB}, H O X C$, and $H O X D$ loci on tiled chips. We probed these chips with DNA amplified by ligation-mediated PCR from ChIPs performed with antibodies specific for H3K27me3, SUZ12, and CBX8 using an antibody for HA as a negative 
A

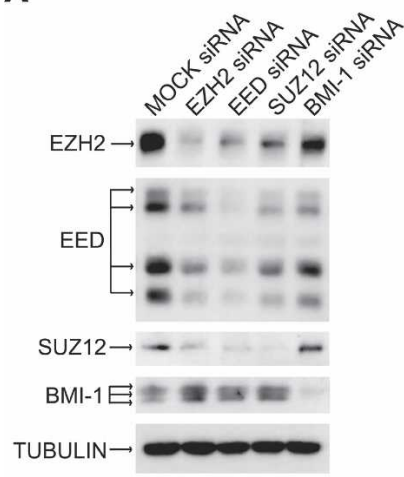

B

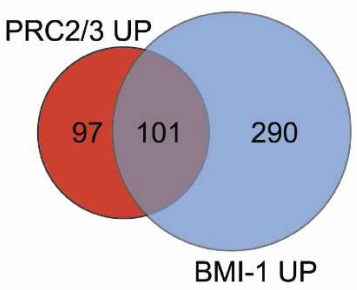

C

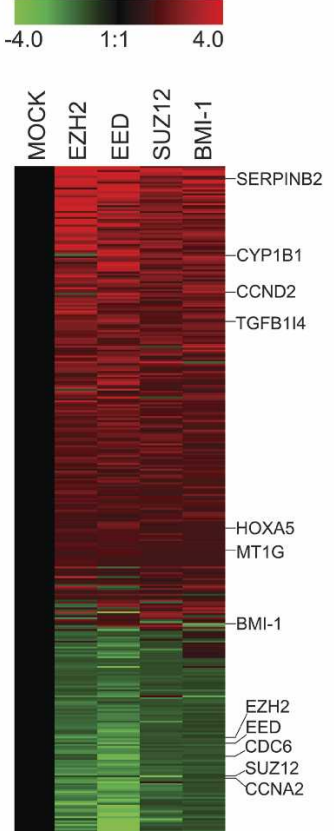

D
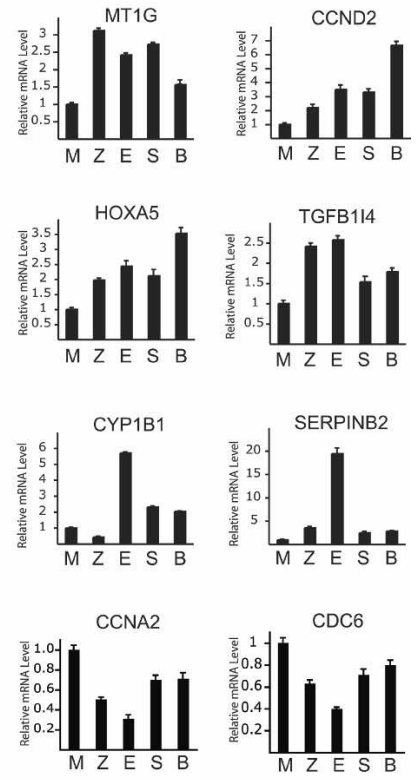

Figure 1. Genome-wide expression screen to identify gene changes in Polycomb depleted cells. $(A)$ Western blot analysis of lysates prepared from TIG3 fibroblasts $44 \mathrm{~h}$ after transfection with siRNA oligos designed to inhibit the expression of EZH2, EED, SUZ12, or BMI-1. Tubulin was used as a loading control. $(B)$ Venn diagram depicting the overlap in genes increased $>1.2$-fold in PRC2 (EZH2, EED, and SUZ12 combined) and PRC1 (BMI-1) depletion. (C) Treeview representation of Affymetrix expression data depicting the gene expression changes in Polycomb-depleted cells. $(D)$ Validation of gene expression changes by qPCR for a selection of genes (indicated in $B$ ). mRNA was prepared from TIG3 cells transfected with Mock (M), EZH2 (Z), EED (E), SUZ12 (S), or BMI-1 (B) siRNAs. The experiments were performed independently of the gene expression array experiments.

control and an antibody for E2F3 as a positive control for the ChIP technique. In Figure 2, A and B, the enrichments observed across the entire HOXA locus are depicted at high resolution in $\log _{2}$ and normal scale, respectively. Very strong enrichments of SUZ12, CBX8, and H3K27me3 were observed immediately downstream of the HOXA9 gene and extend upstream of the HOXA13 gene, a stretch of $\sim 45 \mathrm{~kb}$. Interestingly, the enrichments observed on the HOXA9-13 genes "blanket" their complete gene loci, and are not restricted to their promoter regions. Similar robust enrichments were observed on the HOXB, HOXC, and HOXD loci (Supplementary Fig. S1). As a further confirmation of the antibody specificity, we did not observe any significant enrichment of PcGs or H3K27me3 on a large number of control genes, including the E2F target genes CDC6 and CCNA2 (Supplementary Fig. S2).

To validate the enrichment profiles observed on the tiled chips, we quantified the immunoprecipitated DNA enrichments by qPCR of an independent ChIP experiment using primers designed within the promoter regions of all the HOXA genes (Fig. 2C). This established that EZH2 binds along the HOXA locus with an almost identical profile to SUZ12, CBX8, and H3K27me3. Significantly, Polymerase II was only detected at the promoters of the HOXA4 and HOXA5 genes, which are the only paralogs expressed in embryonic fibroblasts, consistent with the fact that these cells are of mesodermal origin.
Identification of target genes whose expression is regulated by the PcGs

Next, we represented the 341 gene loci of the genes identified in the expression array analysis starting from $15 \mathrm{~kb}$ upstream of the transcriptional start site (TSS) and ending $5 \mathrm{~kb}$ downstream of the $3^{\prime}$ end of the last known exon (Supplementary Table 1) on custom designed tiled chips. We hybridized these chips with the DNA used for the analysis of the HOX loci. Specific enrichments of CBX8, SUZ12, and H3K27me3 were detected either at the promoter or elsewhere within the gene locus of 43 genes, represented as a treeview plot in Figure 3A. A detailed description of the exact PcG-binding positions on these genes is given in Supplementary Table 2. We observed enrichments of two types, either in confined "bell curves" that center around a particular point or as the "blanket" type, possibly consisting of multiple peaks fused together. For example, SUZ12, H3K27me3, and CBX8 form bell curve enrichments within the TSS of the $A T F 3, B M P 2$, and DKK2 genes (Fig. 3B; Supplementary Fig. S3), while blanket-type enrichments are observed on the OTX2, CCND2, and MT1G genes (Fig. 3B; Supplementary Fig. S3; Supplementary Table 2). The MT1G gene is part of the metallothionein multigene cluster (MT1E, MT1I, MT1A, MT1B, MT1F, MT1G, and MT1H), which has blanket-type enrichments analogous to the HOX loci (Supplementary Fig. S3; Supplementary Table 3). 
A

$\operatorname{chr7}$\begin{tabular}{lllllllll}
0 & 20 & 40 & 60 & 80 & 100 & 120 & $140 \mathrm{~kb}$ \\
\hline
\end{tabular}
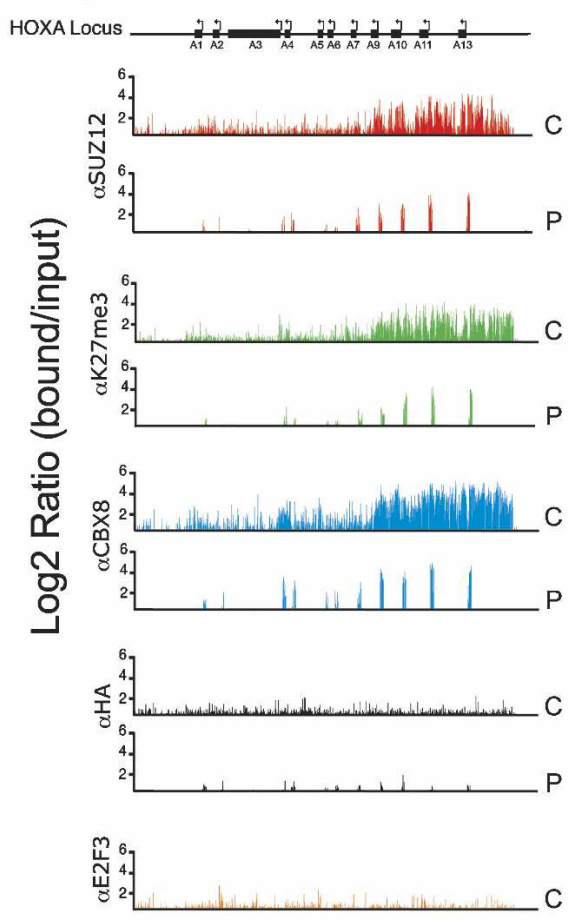

B
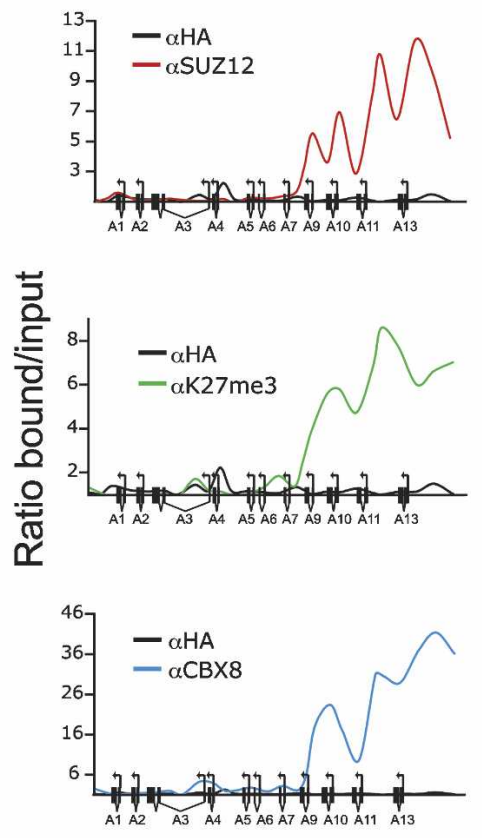

C

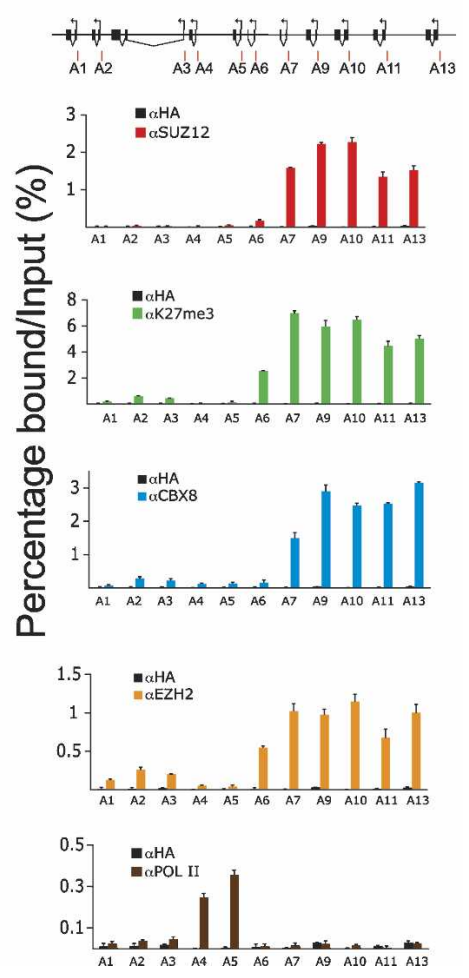

Figure 2. The PcG proteins and H3K27me3 are highly enriched on the HOXA gene cluster. (A) ChIP-on-chip tiling array analysis of the HOXA locus spanning $140 \mathrm{~kb}$ of DNA starting at position 26,880,000 on chromosome 7 . High-resolution mapping of the $140 \mathrm{~kb}$ was achieved by representing 2840 probes of $50 \mathrm{bp}$ with an average spacing of $3 \mathrm{bp}$ between probes. The $Y$-axis represents the Log 2 signal ratios (bound/input) for the indicated antibodies. The results of the promoter ChIP-on-chip experiment are also shown for the HOXA promoters. In this analysis, chips were used containing 24,275 human promoters from 1300 bp upstream to 200 bp downstream of TSS with 15 50-bp probes with an average spacing of 100 bp between probes. (C) Custom ChIP-on-chip data; (P) Promoter ChIPon-chip data. (B) XY scatterplot representation of the data depicted in $A$, created by plotting the average enrichments at 5-kb intervals. (C) Normal ChIP analysis of the promoters of the HOXA gene cluster. Primers were designed within the promoter regions (indicated with red bars) of all HOXA genes as indicated at the top of the panel. Enrichment is shown as percentage input.

Intriguingly, SUZ12 and CBX8 are also found on the $B M I-1$ and $C B X 8$ gene loci and are associated with H3K27me3 enrichments (Fig. 3B; Supplementary Fig. S3). The expression of BMI-1 and CBX8 increases following the siRNA-mediated depletion of other PRC1 or PRC2 members (Figs. 1A, 3A). Therefore, these data suggest that PcG proteins autoregulate their own synthesis. This is conserved during evolution, since PcG proteins bind to the polyhomeotic ( $\mathrm{Ph}$ ) locus in Drosophila (Fauvarque et al. 1995; Bloyer et al. 2003).

Next we validated a selection of these newly identified target genes, for EZH2, SUZ12, CBX8, and H3K27me3 enrichments in an independent experiment (Fig. 3C). The previously identified SUZ12 target gene MYT1 (Kirmizis et al. 2004) was included as a positive control and the HOXA1 and CCNA2 genes as negative controls. Finally, the expression of several target genes $(M T 1 G$, CCND2, SERPINB2, and CYPB1) were tested and shown to be reduced in BMI-1-overexpressing TIG3 cells (data not shown), further validating them as PcG target genes in this cellular system. We conclude that we have iden- tified 43 target genes of the PcG proteins, whose expression changes in PcG-depleted cells.

Perhaps surprisingly, the mRNA transcripts of the previously characterized SUZ12 target gene MYT1 as well the HOXA7-13 genes remained undetectable in PcG-depleted cells (data not shown). This is despite the fact that we observe strong PcG enrichments on their promoters (Figs. 2C, 3C). Therefore, in order to identify all PcG target genes in human embryonic fibroblasts, we decided to perform a global unbiased identification of PcG-bound promoters independent of their expression.

\section{Genome-wide identification of human promoters bound by $P c G$}

We interrogated chips containing probes for $24,275 \mathrm{hu}-$ man promoters within a defined region spanning 1300 base pairs (bp) upstream to $200 \mathrm{bp}$ downstream of the TSS. Significantly, the PcGs bind within this limited promoter region in $70 \%$ of the target genes described in Figure 3A (see Supplementary Table 2). As shown in Fig- 
A
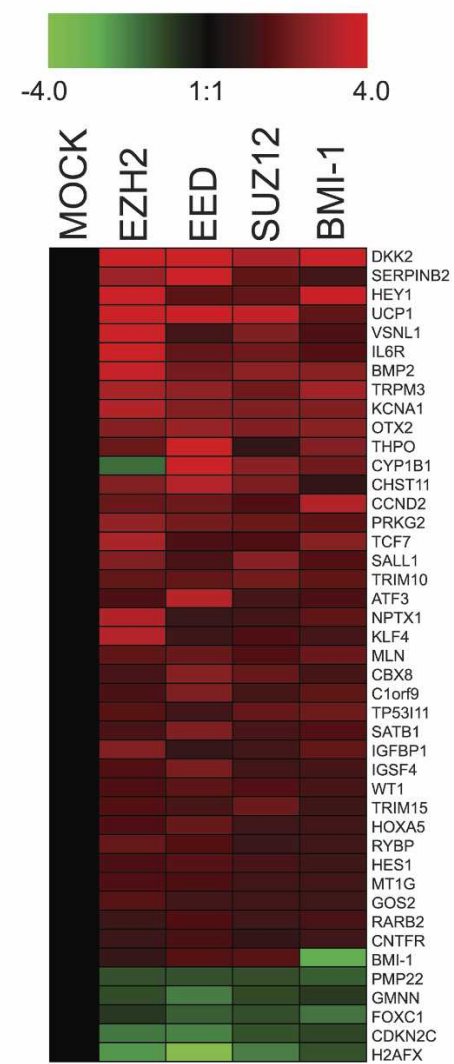

B

BMP2

chr20:6,694,705-6,708,180 chr1:209,162,067-209,183,934

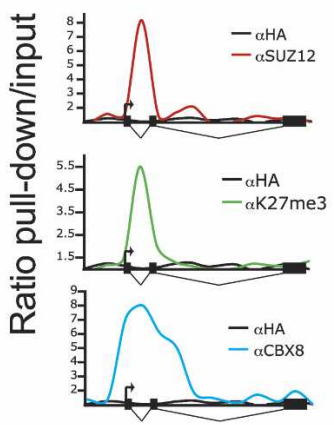

BMI-1 chr10:22,649,609-22,670,156

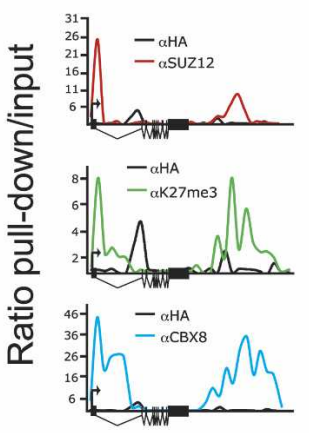

ATF3

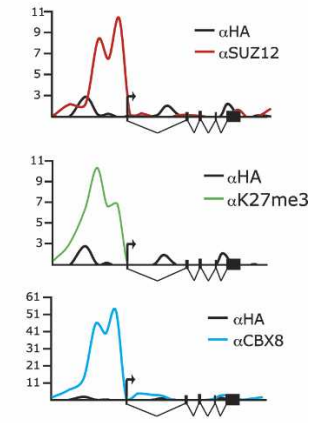

CCND2

chr12:4,248,185-4,289,422

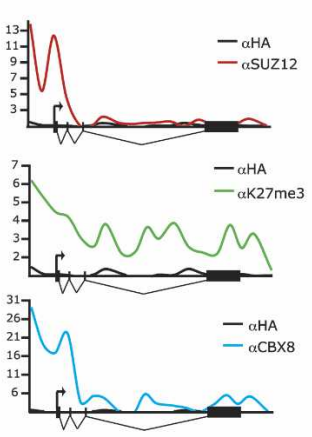

C
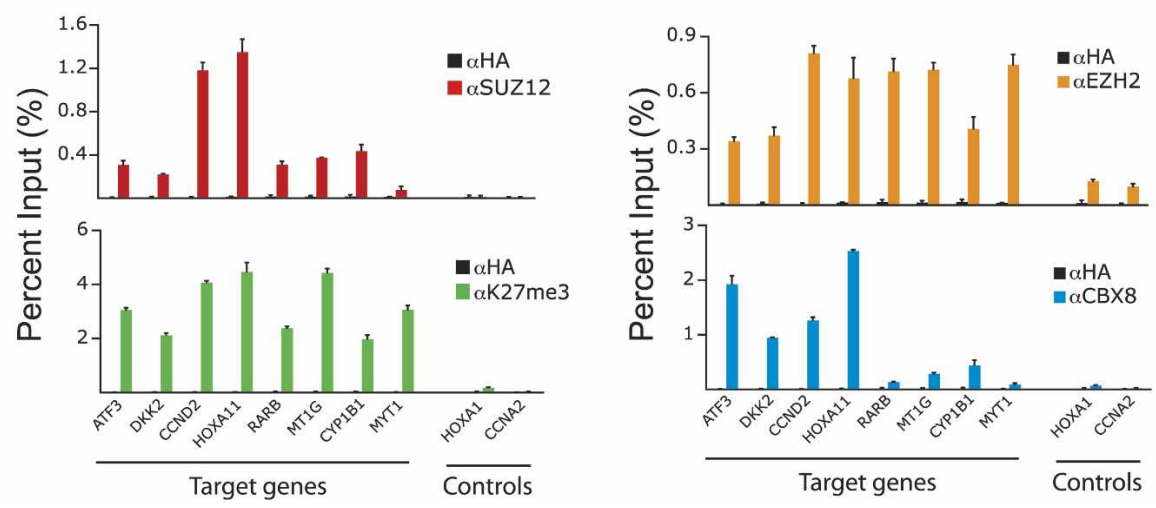

Figure 3. Identification of $43 \mathrm{PcG}$ target genes whose expression changes in Polycomb-depleted cells. $(A)$ Treeview depiction of the expression changes in Polycomb-depleted cells of 43 direct PcG target genes. (B) XY scatterplot representations of SUZ12, H3K27me3, and CBX8 enrichments along the gene loci of $B M P 2, A T F 3, B M I-1$, and CCND2. The chromosome number and the region covered are depicted above each panel. (C) Standard ChIP analysis of newly identified Polycomb target genes using the previously identified MYT1 target gene as a positive control. The CCNA2 and HOXA1 genes are presented as negative controls.

ure 4A and listed in Supplementary Table 3, SUZ12, $\mathrm{CBX} 8$, and $\mathrm{H} 3 \mathrm{~K} 27 \mathrm{me} 3$ are present on a very large number of promoters. A significant enrichment was found for CBX8 (PRC1) on 2487 promoters (10.2\% of the total), for H3K27me3 on 2206 promoters $(9.0 \%)$, and for SUZ12 (PRC2) on 1042 promoters (4.3\%). A very significant overlap was observed between promoters bound by
PRC1 and PRC2, which were also tri-methylated on $\mathrm{H} 3 \mathrm{~K} 27$, consistent with the fact that PRC1 is dependent on PRC2-mediated K27 tri-methylation for its ability to bind to chromatin (Hernandez-Munoz et al. 2005; Pirrotta and Gross 2005). Several genes with H3K27me3 enrichments appeared not to have associated CBX8, suggesting that this mark may execute distinct functions 
Bracken et al.

A

Figure 4. Genome-wide mapping of PcG target promoters. (A) Venn diagram depicts significant overlaps between the presence of SUZ12, CBX8, and H3K27me3 on promoters. $(B)$ A remarkable conservation of Polycomb target genes through evolution from Drosophila to humans. Several confirmed or predicted Drosophila PcG target genes are shown in the left column. In our analysis we have identified their human homologs as being human PcG targets (see Supplementary Table 3). (C) A selection of PcG target genes identified in this study, focusing on those known to be involved in key pathways controlling development, differentiation, stem cell biology, and cell fate decisions.

independent of PRC1 complexes. Alternatively, PRC1 might be bound to these genes through the two chromodomain-containing CBX8 homologs CBX4 or CBX7. The large number of genes identified, which were only significantly bound by CBX8, are unlikely to be CBX8 specific targets. In fact, genes belonging to this category, when subsequently tested in quantitative ChIP analysis, were found to also possess significant $\mathrm{H} 3 \mathrm{~K} 27 \mathrm{me} 3$ and SUZ12 binding, for example, CYP1B1 and DKK2 (cf. Fig. 3C and Supplementary Table 3). Therefore the large number of genes bound only by CBX8 is likely a consequence of the higher affinity of the CBX8 antibody for its epitope rather than a reflection of PRC2-independent recruitment. In conclusion, our results using promoter arrays extend the repertoire of PcG target genes to $>1000$ (Fig. 4A; Supplementary Table 3).

Next we asked: What is the nature of the target genes identified? Remarkably, we found that the majority of the genes previously identified or predicted to be PcG target genes in Drosophila have human homologs identified as PcG targets in this screen (Fig. 4B; Ringrose and Paro 2004; Ringrose et al. 2004). In addition to the HOX genes, we found that Engrailed, Hedgehog, Hairy, and Caudal all have human PcG target homologs. Interestingly, another target in Drosophila is the Polyhomeotic
B
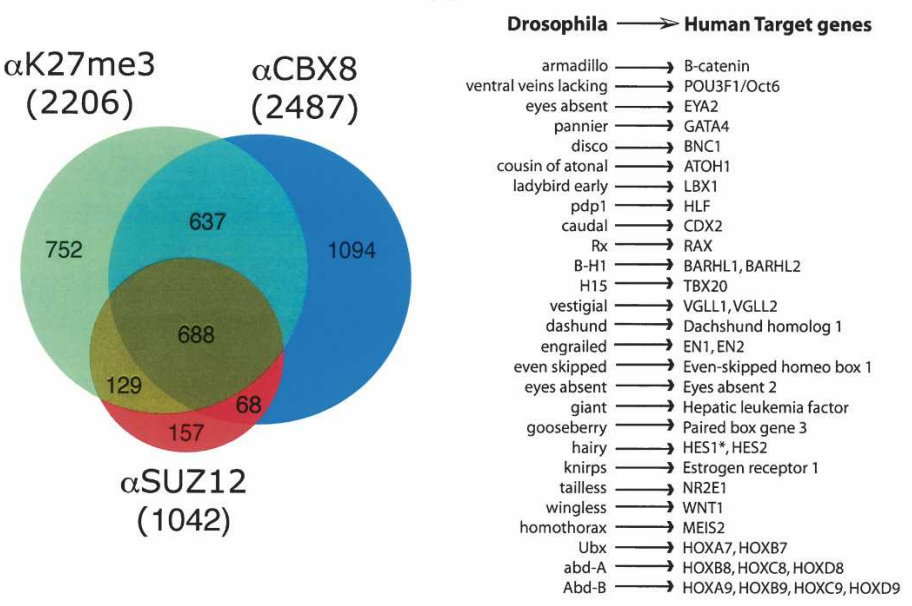

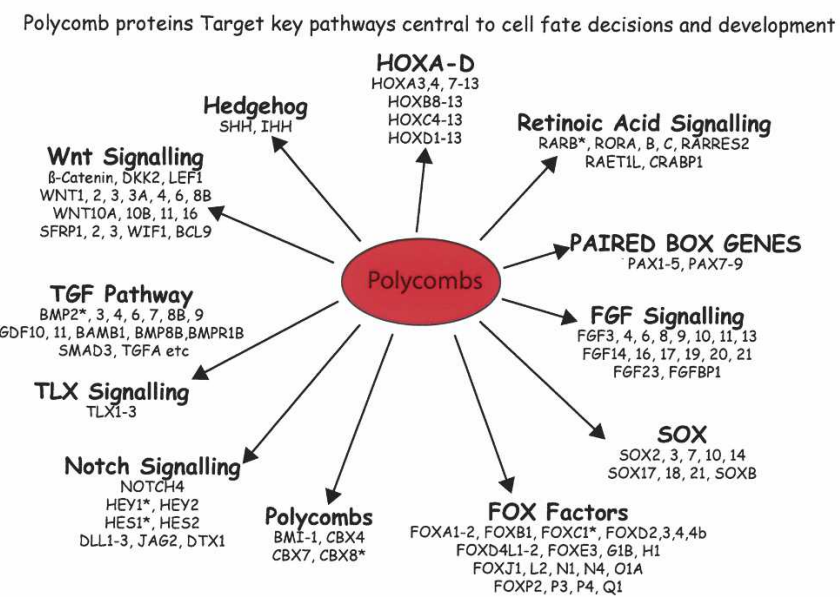

locus. As mentioned above, we have found that the human PcGs also bind to the BMI-1 and CBX8 gene loci, and now extend this group to include the CBX4 and CBX7 loci.

PcGs target both stem cell- and differentiation-specific genes

We wished to study PcG dynamics on target genes in a biologically relevant model of differentiation. The global mapping analysis revealed that the PcGs bind many genes that are specifically induced in various types of differentiation (Table 1). For example, BMP6 (Kugimiya et al. 2005), the homebox gene PAX4 (Wang et al. 2004), MYOG (Rohwedel et al. 1994), DMBT1 (Al-Awqati 2003), and ZIC1 (Sato et al. 2005) are specific differentiation factors induced in osteogenesis, endocrinal differentiation, myogenesis, epithelial cell differentiation, and neurogenesis, respectively. Recent results have shown that EZH2 represses the muscle creatine kinase gene $C K M$ in nondifferentiated myoblasts and is displaced from the gene promoter upon muscle differentiation, when the gene becomes activated (Caretti et al. 2004). Our results show that the PcGs target a large number of tissue-specific differentiation genes like CKM (see Table 
Table 1. Examples of differentiation genes identified by PcG ChIP-on-chip

\begin{tabular}{|c|c|c|c|c|c|}
\hline \multirow[b]{2}{*}{ Gene name } & \multirow[b]{2}{*}{ Function } & \multicolumn{3}{|c|}{ Antibodies used } & \multirow[b]{2}{*}{$\alpha \mathrm{K} 27 \mathrm{me} 3$} \\
\hline & & $\alpha \mathbf{H A}$ & $\alpha \mathrm{CBX8}$ & $\alpha \mathrm{SUZ12}$ & \\
\hline DLX5 & Neuronal differentiation & & + & + & + \\
\hline HEY2 & Neuronal differentiation & & + & + & + \\
\hline LHX1 & Neuronal differentiation & & + & + & + \\
\hline MASS1 & Neuronal differentiation & & + & + & + \\
\hline NEFL & Neuronal differentiation & & + & + & + \\
\hline NEUROD1 & Neuronal differentiation & & + & + & + \\
\hline NEUROG1 & Neuronal differentiation & & + & + & + \\
\hline NEUROG2 & Neuronal differentiation & & + & + & + \\
\hline NMU & Neuronal differentiation & & + & + & + \\
\hline NXPH2 & Neuronal differentiation & & + & + & + \\
\hline OLIG2 & Neuronal differentiation & & + & + & + \\
\hline PAX3 & Neuronal differentiation & & + & + & + \\
\hline PHOX2A & Neuronal differentiation & & + & + & + \\
\hline PHOX2B & Neuronal differentiation & & + & + & + \\
\hline POMC & Neuronal differentiation & & + & + & + \\
\hline POU4F2 & Neuronal differentiation & & + & + & + \\
\hline ROBO3 & Neuronal differentiation & & + & + & + \\
\hline SEMA5B & Neuronal differentiation & & + & + & + \\
\hline SIM1 & Neuronal differentiation & & + & + & + \\
\hline TBR1 & Neuronal differentiation & & + & + & + \\
\hline ZIC1 & Neuronal differentiation & & + & + & + \\
\hline BMP3 & Bone differentiation & & + & & \\
\hline TNFSF11 & Bone differentiation & & + & & + \\
\hline CHRDL2 & Bone differentiation & & + & + & + \\
\hline BMP6 & Bone differentiation & & + & & \\
\hline GDF2 & Bone differentiation & & + & & + \\
\hline BMP7 & Sex differentiation & & & + & + \\
\hline JAG2 & Sex differentiation & & & & + \\
\hline DMRT1 & Sex differentiation & & + & + & + \\
\hline DMRT2 & Sex differentiation & & + & + & + \\
\hline DMRT3 & Sex differentiation & & + & + & + \\
\hline SRY & Sex differentiation & & + & & \\
\hline DMRTA1 & Sex differentiation & & + & & + \\
\hline BMP8B & Sex differentiation & & + & & + \\
\hline FGF9 & Sex differentiation & & + & & \\
\hline CD4 & T-cell differentiation & & & & + \\
\hline MDFI & Chondrogenic differentiation & & + & + & + \\
\hline CSRP3 & Muscle development & & + & & \\
\hline MYOG & Muscle development & & + & & + \\
\hline SYNE1 & Muscle development & & + & & \\
\hline CKM & Muscle development & & & + & + \\
\hline MYH11 & Muscle development & & + & + & + \\
\hline $\mathrm{ACHE}$ & Muscle development & & + & + & + \\
\hline TNNT1 & Muscle development & & + & + & + \\
\hline HAND2 & Cardiogenesis & & + & & \\
\hline DLL1 & Cell fate/Notch pathway & & + & & \\
\hline DLL3 & Cell fate/Notch pathway & & + & + & + \\
\hline NOTCH4 & Cell fate/Notch pathway & & + & & + \\
\hline PAX4 & Endocrine differentiation & & + & + & + \\
\hline EDAR & Epidermal cell differentiation & & + & & + \\
\hline DMBT1 & Epithelial cell differentiation & & + & & + \\
\hline THPO & Hematopoiesis & & + & + & + \\
\hline KIT & Hematopoiesis & & + & + & + \\
\hline LIF & Hematopoiesis & & + & & \\
\hline KDR & Hematopoiesis & & + & & + \\
\hline TAL1 & Hematopoiesis & + & + & + & + \\
\hline BMP4 & Mesoderm cell fate decisions & & + & & \\
\hline $\mathrm{SHH}$ & Mesoderm cell fate decisions & & + & + & + \\
\hline
\end{tabular}

A selection of enriched target genes identified in the ChIP-on-chip analysis using a 24,275 tiled promoter array. 
$1)$, suggesting that the displacement of PcGs from differentiation-specific genes during terminal differentiation is a general phenomenon (depicted in Fig. 5A, panel i).

To test this, we chose to focus on neuronal differentiation for several reasons. A large number of neuronal differentiation genes are bound by PcGs (Table 1). The PcGs are required for neuronal development and selfrenewal of neural stem cells (Leung et al. 2004; Molofsky et al. 2004). Additionally, there are several well-established model systems for neuronal differentiation processes. As a model system, we chose the human embryonic teratocarcinoma cell line NT2/D1, which has neural progenitor cell properties and irreversibly differentiates along a neural lineage upon treatment with retinoic acid (RA) (Lee and Andrews 1986).

We selected four genes based on their proposed role in neuronal differentiation: the gene for the zinc-finger domain transcription factor ZIC1 required for normal neuronal differentiation (Grinberg and Millen 2005); the homeobox-containing transcription factor MEIS2; the RA receptor $\beta, R A R B$; and the gene for neurofilament light chain, NEFL (Zhu et al. 1997). The expression of these genes is induced during differentiation (Zhu et al. 1997; Niederreither et al. 2000) and during RA-induced differentiation of NT2/D1 cells (Fig. 5B; data not shown). Consistent with the increased expression of these genes during differentiation, we observed a progressive decrease in PcG binding and H3K27me3 enrichments on these genes (Fig. 5B; data not shown). These data are consistent with the model depicted in Figure 5A, panel i, and since the PcGs associate with a large number of tissue-specific genes in differentiated cells, this suggests that the differentiation specific signals, which activate tissue-specific genes, lead to the displacement of PcGs from the genes.

Subsequently we decided to investigate PcG target genes, which become silenced during differentiation. A potential model for how this would occur is depicted in Figure 5A, panel ii, in which we speculate that PcGs would be recruited during differentiation. To test this hypothesis, we selected three genes that are highly expressed in neuronal progenitor cells but silenced during differentiation (Fig. 5C). These included genes for the basic helix-loop-helix (bHLH) proneural transcription factors OLIG2 (Lee et al. 2005) and NEUROG2 (Ma et al. 1996), and the gene for metallothionein 1G, MT1G. ChIP experiments showed, in contrast to our expectations, a strong and significant binding of PcGs together with the presence of $\mathrm{H} 3 \mathrm{~K} 27 \mathrm{me} 3$ on the promoters of these genes in undifferentiated cells (Fig. 5C), with only slight increases during differentiation. These results demonstrate that binding of PcGs to target genes in undifferentiated cells does not strictly correlate with transcriptional silencing.

To understand if this intriguing result could be extended to other genes, we analyzed the binding of the PcGs to the HOXA locus before and after differentiation of the NT2/D1 cells. Previous data have shown that the $H O X$ genes display faithful regulation patterns following RA-induced differentiation of NT2/D1 cells (Simeone et al. 1990; Houldsworth et al. 2002). As depicted in Figure
6A and shown in Figure 6B, the (posterior) 5 '-end genes (HOXA7-13) are expressed in undifferentiated cells but are dramatically repressed upon RA treatment. In contrast, the genes at the (anterior) $3^{\prime}$ end of the locus (HOXA1-5) become strongly activated. We determined the binding of EZH2 and CBX8 together with H3K27me3 enrichments on the complete HOXA locus both before and after induction to differentiate. Consistent with the genes analyzed in Figure 5, the PcGs are displaced from the activated HOXA1-5 gene loci during differentiation, while they are already bound to the HOXA7-13 genes in undifferentiated NT2/D1 cells (Fig. 6C) and remain bound throughout the differentiation process and subsequent decrease in mRNA expression. These results on the HOXA cluster expand the set of genes, which are transcriptionally active in undifferentiated cells yet bound by PcGs prior to their repression in differentiated cells.

\section{Discussion}

By genome-wide location analysis, we have identified $>1000$ putative genes bound by PcG proteins. Strikingly, these genes contain the key members of the Wnt, TGF $\beta$, FGF, Notch, and Hedgehog signaling pathways known to be the regulators of developmental and differentiation processes. In addition, target genes are conserved throughout evolution from Drosophila to human, suggesting that this transcriptional regulatory network is essential for the development and differentiation of all multicellular organisms.

\section{Polycomb target genes}

By performing gene expression profiling of human embryonic fibroblasts in combination with ChIP-on-chip experiments, we identified 43 PcG target genes whose expression is dependent on the PcGs. The large majority of these genes become derepressed as a result of specific depletion by siRNAs of the PRC2 components (EZH2, EED, and SUZ12) or the PRC1 component BMI-1 (39 of 43). These target genes include several known markers of bone, cartilage, and fat differentiation (Supplementary Table 2). To put this into context, fibroblasts are proliferating cells of the mesoderm that compose part of the connective tissue in almost every tissue and organ. They are derived from mesenchymal stem cells, which are multipotent precursors, capable of differentiating into osteoblasts, adipocytes, chrondrocytes, endothelial cells, and also non-mesoderm-type lineages, such as neuronallike cells (Kassem 2004). Interestingly, evidence exists that embryonic fibroblasts in tissue culture maintain at least some of the multipotency of mesenchymal stem cells. For example, mouse embryonic fibroblasts can undergo chrondrogenic and adipocytic differentiation /Ge et al. 2002; Lengner et al. 2004). Consistent with this, we found that several markers of osteocytic, chrondrocytic, adipocytic, and neural differentiation are up-regulated in Polycomb-depleted cells (Fig. 3A; Supplementary Table 
A

i) PcG are released from targets during terminal differentiation

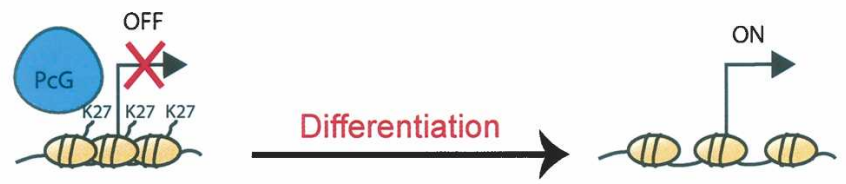

ii) Classic model of PcG mediated repression on HOX genes

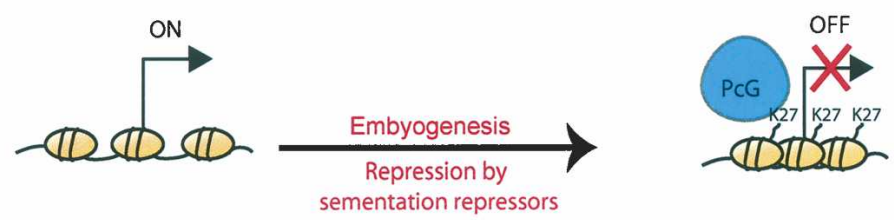

B

Polycomb target genes induced during neuronal differentiation
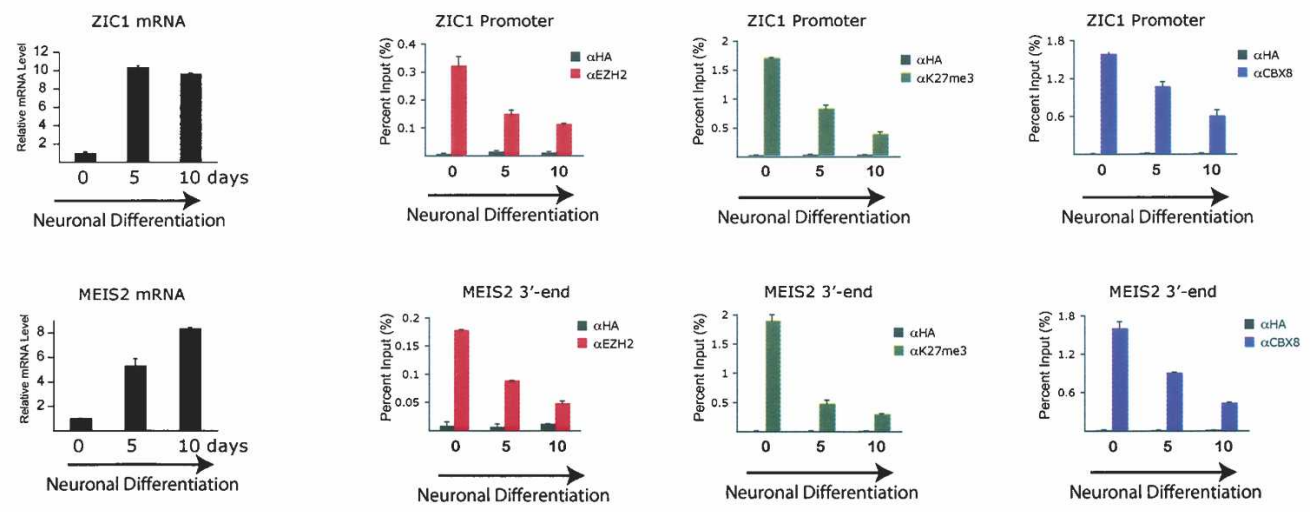

\section{C}

\section{Polycomb target genes repressed during neuronal differentiation}
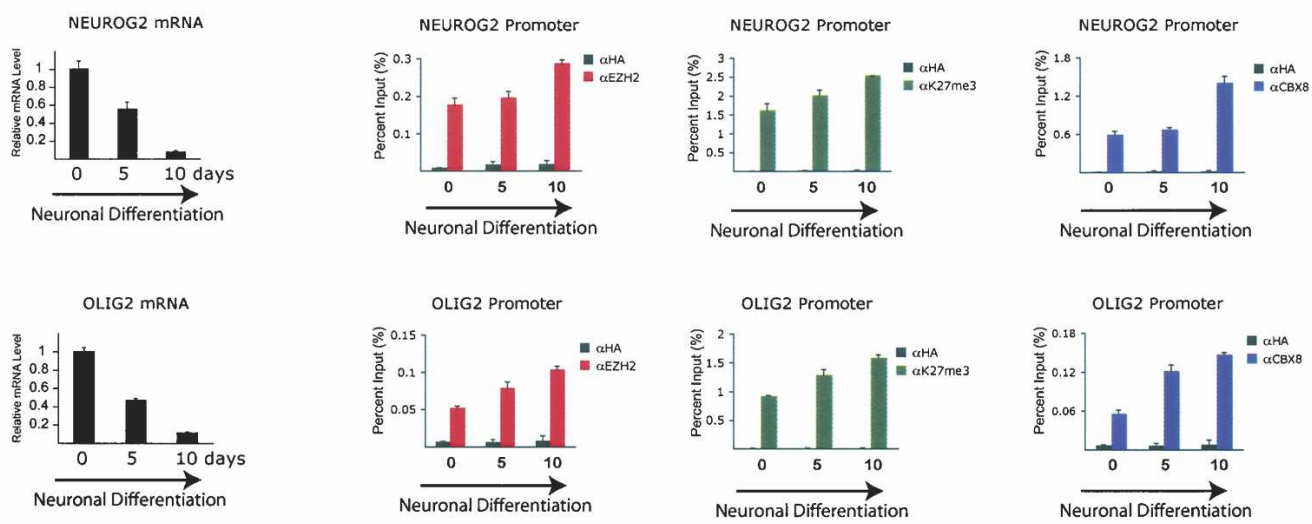

Figure 5. PcGs bind to genes that are repressed or induced during neuronal differentiation. $(A)$ Models for how PcGs could regulate gene expression during terminal differentiation. (B) qPCR and ChIP analysis of two PcG target genes (ZIC1 and MEIS2) induced during neuronal differentiation of NT2/D1 cells treated with $1 \mu \mathrm{M}$ RA. (C) qPCR and ChIP analysis of two genes (NEUROG2 and OLIG2) repressed during neuronal differentiation of NT2/D1 cells treated with $1 \mu \mathrm{M}$ RA. 
A

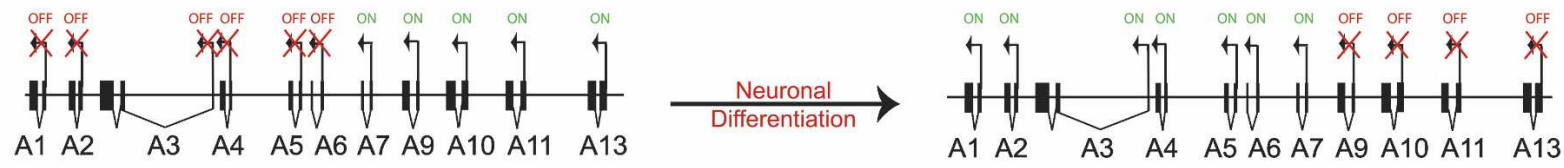

B

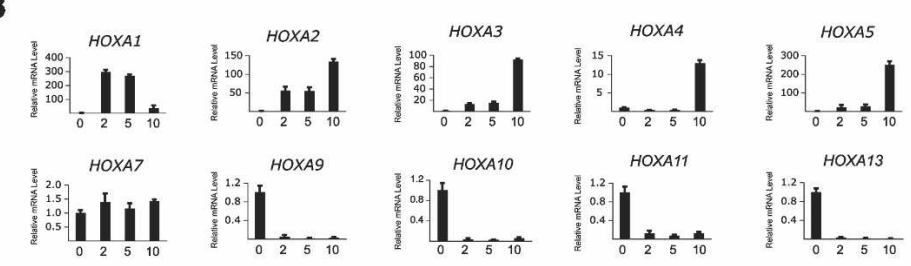

C

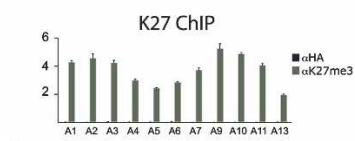

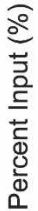
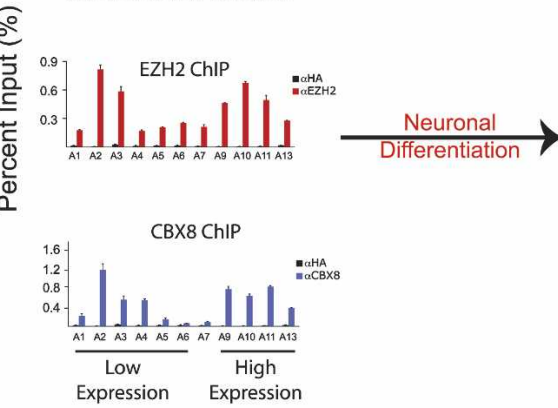

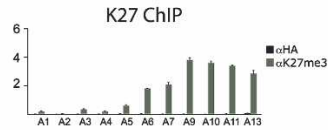

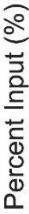

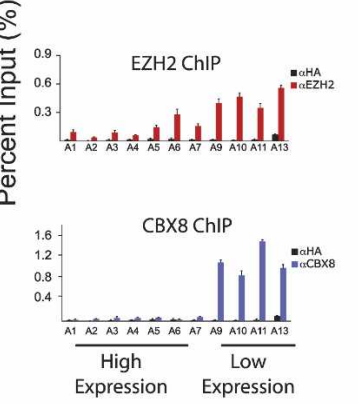

D

Displacement of PcG's from targets during differentiation

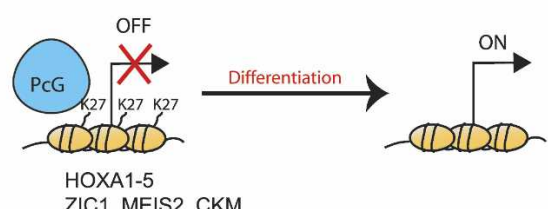

E

Polycomb "pre-programing" of certain target genes in non-differentiated cells

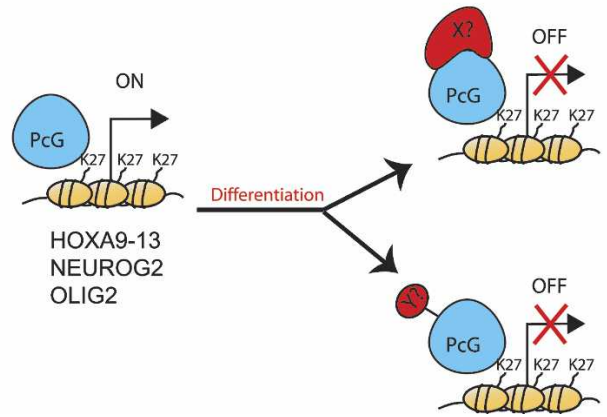

Figure 6. Polycombs are present on active $H O X$ genes in nondifferentiated cells. $(A)$ Schematic depiction of the gene expression changes along the HOXA locus upon RA-mediated induction of neuronal differentiation. $(B)$ Quantification of mRNA expression changes of HOXA genes during neuronal differentiation of NT2/D1 cells by qPCR. (C) ChIP analysis of EZH2, H3K27me3, and CBX8 binding to the promoters of the HOXA1 to HOXA13 genes both before and after $10 \mathrm{~d}$ of RA treatment. $(D)$ Displacement of PcGs from target genes activated during differentiation, for example, ZIC1, MEIS2, RARB, and HOXA1-5 in neuronal differentiation and CKM in myoblast differentiation. (E) Polycomb "preprogramming" of certain target genes in undifferentiated cells, for example, NEUROG2, OLIG2, and HOXA9-13. These genes are paradoxically expressed while being bound by PcGs in undifferentiated cells. Several hypothetical mechanisms for the triggering of PcG repressive function during differentiation are possible, include post-translational modifications of the PcGs, addition of H1K26me3 or ubiquitinated H2A-K119 marks, recruitment of DNA methyltransferases, the binding of additional transcriptional repressors, or a combination of these mechanisms.

2). For example, both the bone morphogenic protein BMP2 and the Wnt/ $\beta$-catenin signaling protein $D K K 2$ function in terminal osteoblast differentiation (Li et al. 2005). While HEY1 and TCF7 are transcriptionally activated during osteogenesis (de Jong et al. 2004), both CHST11 (Kluppel et al. 2005) and PRKG2 (Chikuda et al. 2004) are associated with chrondrocytic differentiation, the latter being a molecular switch from proliferation to hypertrophic differentiation of chondrocytes. The G0S2 protein is involved in adipocyte differentiation (Zandbergen et al. 2005), and UCP1 is a specific marker of Brown adipose tissue. In addition, several other target genes are known regulators of development such as $R A R B, W T 1$, and the homeobox genes SALL1 and HOXA5. In summary, the combination of ChIP-on-chip and expression array analysis in human embryonic fibroblasts has identified 43 novel PcG target genes with important regulatory roles in mesenchymal differentiation and development.
Strikingly, the expression of only a relatively small number of the $>1000$ identified PcG target genes was affected by depleting PcGs in human embryonic fibroblasts, and $>90 \%$ of the identified target genes are not detectably expressed. This is consistent with previous observations by Kirmizis et al. (2004) in SW480 colon cancer cells depleted of SUZ12. We hypothesize that the majority of the 1000 PcG target genes identified here in fibroblasts are permanently silenced. This permanent repression could be due to secondary epigenetic modifications of the target promoters by, for example, the EZH2 complex itself or by DNA methylation. Supporting this notion is the demonstration that EZH2 possesses $\mathrm{H} 1 \mathrm{~K} 26$ methylation activity (Kuzmichev et al. 2004), and since H1K26me3 can tether HP1 to chromatin (Daujat et al. 2005), this could add an additional layer of transcriptional repression on PcG target genes. Additionally, the expression of EZH2 has recently been shown to be sufficient for the recruitment of DNA methyl transferases 
to cellular promoters leading to their DNA methylation and repression (Vire et al. 2005). It is possible that such secondary repressive modifications are not alleviated in PcG-depleted cells. As an alternative and complementary explanation for the lack of expression of a large number of PcG target genes in fibroblasts, we suggest that the fibroblasts may lack the specific transcriptional activators required for the expression of the tissue-specific target genes such as those listed in Table 1.

\section{Polycomb target genes and cancer}

The identification of PcG target genes may also provide vital mechanistic insights into the precise nature by which PcGs contribute to cancer. It has been proposed that cancer originates from nondifferentiated or stem cell-like cells, referred to as "cancer stem cells" (Reya et al. 2001). This idea is supported by the recent observation that mammary stem cells are enriched in premalignant breast tissue (Shackleton et al. 2006). The identification of a large number of PcG target genes required for differentiation (Table 1) strongly suggests that the oncogenic potential of genes such as BMI-1 and EZH2 can be ascribed to their role in stem cell maintenance. Another insight comes from the fact that a significant proportion of the identified PcG genes are silenced in cancer by DNA methylation of their promoter sequences. These include RARB, CCND2, MT1G, KLF4, IGSF4, WT1, NPTX1, HOXA5, BMP2, and GOS2 (Evron et al. 2001; Loeb et al. 2001; Fackler et al. 2003; Fukami et al. 2003; Hagihara et al. 2004; Zhao et al. 2004; Henrique et al. 2005; Lewis et al. 2005). Significantly, as pointed out above, EZH2 has recently been shown to act as a platform for DNA methyltransferases on certain EZH2 target genes (Vire et al. 2005). The PRC2 complex could therefore contribute to cancer development by specifically silencing tumor-suppressor genes by DNA methylation. Consistent with this, we have found an inverse correlation between the expression levels of the PcGs, EZH2, SUZ12, and BM1-1, and the target genes $M T 1 G$, HOXA5, and RARB in breast cancer (A.P. Bracken, P. Cloos, and S. Confalonieri, unpubl.). It will be important in future investigations to determine if the silencing of these genes in cancer contributes to the development of the disease and if PcGs have a causal role in this.

Delineating the mechanisms by which PcGs regulate cell fate decisions

The identification of genes bound by PcGs has enabled us to begin to address the mechanisms by which they repress transcription. Our results, based on a model of neuronal differentiation, suggest at least two alternative mechanisms (depicted in Fig. 6D,E). The first model is exemplified by genes such as ZIC1, MEIS2, and HOXA15, which are bound and repressed by PcGs in undifferentiated cells. Upon induction to differentiate, PRC1 and PRC2 are displaced from these genes by, as yet, unidentified mechanism(s), leading to their derepression. This model is consistent with previous results, suggesting a similar role for the PcGs in muscle and germ cell terminal differentiation processes (Caretti et al. 2004; Chen et al. 2005) and predicts that this is a general phenomenon.

The alternative model describes when PcG target genes are down-regulated during differentiation (Fig. 6E). This model is based on the surprising observation that the PcGs, in some cases, are bound to their target genes in undifferentiated cells, despite the gene being actively expressed. Based on our results for OLIG2, NEUROG2, and HOXA9-13, we propose that these PcG target genes are already "preprogrammed" to be repressed upon appropriate cell fate signals. Supporting this hypothesis, the Paro laboratory demonstrated that the Drosophila PcG and Trithorax proteins bind to Polycomb-Responsive Elements (PREs) and promoters of $H O X$ genes before their expression levels are set by the early-acting segmentation factors (Orlando et al. 1998). Further supporting such a concept, we observed H3K27me3 and SUZ12 enrichments on the entire HoxA locus in mouse embryonic stem cells, resembling the profile observed in undifferentiated NT/D1 cells (Fig. 6C; Supplementary Fig. S4; data not shown). This suggests that the transcriptional memory system of the HOX genes and other genes controlling cell fate are preset or "programmed," possibly by PcGs in the zygote generated from maternal mRNA. In this model, specific developmental signals such as RA concentrations could trigger the PcG-repressive capacity by as yet unidentified mechanisms. This could involve the post-translational modifications of the PcG proteins, the modification of other proteins/histones by the PcGs, or the specific recruitment/dissociation of transcriptional regulators from the PcG target genes (Fig. 6E). Therefore, we propose that the PRCs function as "platforms" for channeling repressive signals during developmental and differentiation processes.

In summary, we predict that PcGs form part of an epigenetic blueprint for development and differentiation established early in embryogenesis. Future investigations may hopefully unravel the precise mechanistic contributions of PcG proteins, modifications such as H1K26me3 and ubiquitinated H2A-K119 and associated proteins, such as HP1 and DNA methyltransferases, on the $>1000$ genes identified here during multiple types of cell fate decisions. An additional challenge for the future will be to harness this knowledge such that we can dedifferentiate or trans-differentiate cells for therapeutic purposes.

\section{Materials and methods}

\section{Tissue culture}

The human diploid embryonic lung fibroblast TIG3 cell line and the embryonic carcinoma cell line NTERA2 (NT2/D1) (Lee and Andrews 1986) were grown in DMEM supplemented with $10 \%$ (v/v) FCS. To induce differentiation of NT2/D1 cells, asynchronously growing cells were seeded at $30 \%$ confluency and were treated $24 \mathrm{~h}$ later with $1 \mu \mathrm{M}$ ATRA (dissolved in DMSO; Sigma). Cultures treated continuously with RA were collected at $0,2,5$, and $10 \mathrm{~d}$ for RNA extraction or harvested for ChIP at 0, 5, and 
$10 \mathrm{~d}$. Cultures were reseeded every 3-4 d and collected no less than $24 \mathrm{~h}$ after reseeding.

\section{Generation of antibodies}

Two polyclonal CBX8 (hPc3) antibodies "LAST" and "GALD" were produced in rabbits using synthetic peptides corresponding to amino acids 107-129 (KKPGRSPQDLASTSRAREGLRN MGL) and 295-318 (KKGQGALDPNGTRVRHGSGPPSSGG) of human CBX8, respectively. These were coupled to Keyhole Limpet Hemocyanin (KLH) through the N-terminal lysine residues and injected subcutaneously into rabbits according to standard procedures (DAKO). Positive sera produced were affinity-purified on the respective peptide antigens according to standard procedures. For ChIP assays, $5 \mu \mathrm{g}$ of a pool of both affinitypurified antibodies was used per immunoprecipitation.

\section{siRNA interference}

Specific siRNA oligos targeting EZH2, EED, SUZ12, and BMI-1 mRNAs were described previously (Bracken et al. 2003; Pasini et al. 2004b). Cells were transfected using Oligofectamine (Invitrogen) and harvested $44 \mathrm{~h}$ after transfection.

\section{Quantification of $m R N A$ levels by $q P C R$}

cDNA was generated by RT-PCR using the PE Applied Biosystems TaqMan Reverse Transcription Reagents. Reactions were determined using the SYBR Green I detection chemistry system (Applied Biosystems), using an ABI Prism 7300 Sequence Detection System. Ubiquitin was used as a control gene for normalization. The sequences of the primers used are available upon request.

\section{Affymetrix expression analysis}

Total RNA was extracted from mock, EZH2, EED, SUZ12, and BMI-1 siRNA-transfected cells. For each treatment, RNA was prepared from six independent experiments and was pooled into one sample to reduce the experimental variation. Targets for microarray hybridization were synthesized accordingly to the supplier's instructions (Affymetrix). The human GeneChip array U133A (Affymetrix), which interrogates $\sim 33,000$ transcripts, was used for gene expression profiling. Fifteen GeneChip arrays U133A were used for this analysis; for each different condition, three separate arrays were hybridized with pooled cRNA. Hybridization, washing, staining, scanning, and data analysis were performed at The Affymetrix Microarray Unit at the IFOM-IEO campus, Milan, Italy, according to the manufacturer's instructions. Expression levels were analyzed using Microarray Analysis Suite (MAS) 5.0 statistical algorithm software (Affymetrix), using the default parameters and scaling (TGT Value) signal intensities for all the GeneChip arrrays to a value of 500. The mock siRNA treatment was used as a baseline condition for comparison with the polycomb siRNA-treated samples.

\section{ChIP assays}

ChIPs were performed and analyzed essentially as described previously (Bracken et al. 2003). The antibodies used were rabbit anti-E2F3 (sc-878; Santa Cruz), anti-PolII (sc-899; Santa Cruz), anti-H3K27me3 (Upstate), anti-SUZ12 (Upstate), anti-HA (sc805; Santa Cruz), a mouse monoclonal specific for EZH2 (AC22) (Pasini et al. 2004b), and an equal mix of the polyclonal antibodies for CBX8, described above. For normal chromatin IPs, the immunoprecipitated DNA was quantified by real-time qPCR.
The sequences of the PCR primers are available upon request. Instead for the ChIP-chip analysis, the immunoprecipitated DNA was amplified by LMPCR as described previously (Ren et al. 2000) and hybridized to tiled arrays manufactured by NimbleGen Systems, Inc. (http://www.nimblegen.com).

\section{Acknowledgments}

We thank Simone Minardi at The Affymetrix Microarray Unit of The IFOM-IEO campus (Milan, Italy) for help with the expression array experiments, Matteo Cesaroni and Rehanah Boup for their help with data analysis, and Henrik Winther at DAKO (Denmark) for the production of anti-sera to CBX8. We thank Michael Lees and Claus S. Sørensen for critical reading of the manuscript and Anders H. Lund, Bruno Amati, Ernesto Guccione, Marco Ciró, and members of the Helin laboratory for discussions. This work was supported by grants from the Association for International Cancer Research, the Danish Cancer Society, the Novo Nordisk Foundation, the Danish Medical Research Council, the Danish Natural Science Research Council, and the European Commission's 6th Framework Programme.

\section{References}

Al-Awqati, Q. 2003. Terminal differentiation of intercalated cells: The role of hensin. Annu. Rev. Physiol. 65: 567-583.

Bloyer, S., Cavalli, G., Brock, H.W., and Dura, J.M. 2003. Identification and characterization of polyhomeotic PREs and TREs. Dev. Biol. 261: 426-442.

Bracken, A.P., Pasini, D., Capra, M., Prosperini, E., Colli, E., and Helin, K. 2003. EZH2 is downstream of the pRB-E2F pathway, essential for proliferation and amplified in cancer. EMBO I. 22: 5323-5335.

Cao, R. and Zhang, Y. 2004. The functions of E(Z)/EZH2-mediated methylation of lysine 27 in histone H3. Curr. Opin. Genet. Dev. 14: 155-164.

Cao, R., Tsukada, Y., and Zhang, Y. 2005. Role of Bmi-1 and Ring1 A in H2A ubiquitylation and Hox gene silencing. Mol. Cell 20: 845-854.

Caretti, G., Di Padova, M., Micales, B., Lyons, G.E., and Sartorelli, V. 2004. The Polycomb Ezh2 methyltransferase regulates muscle gene expression and skeletal muscle differentiation. Genes \& Dev. 18: 2627-2638.

Chen, X., Hiller, M., Sancak, Y., and Fuller, M.T. 2005. Tissuespecific TAFs counteract Polycomb to turn on terminal differentiation. Science 310: 869-872.

Chikuda, H., Kugimiya, F., Hoshi, K., Ikeda, T., Ogasawara, T., Shimoaka, T., Kawano, H., Kamekura, S., Tsuchida, A., Yokoi, N., et al. 2004. Cyclic GMP-dependent protein kinase II is a molecular switch from proliferation to hypertrophic differentiation of chondrocytes. Genes \& Dev. 18: 2418-2429.

Daujat, S., Zeissler, U., Waldmann, T., Happel, N., and Schneider, R. 2005. HP1 binds specifically to Lys26-methylated histone H1.4, whereas simultaneous Ser27 phosphorylation blocks HP1 binding. J. Biol. Chem. 280: 38090-38095.

de Jong, D.S., Vaes, B.L., Dechering, K.J., Feijen, A., Hendriks, J.M., Wehrens, R., Mummery, C.L., van Zoelen, E.J., Olijve, W., and Steegenga, W.T. 2004. Identification of novel regulators associated with early-phase osteoblast differentiation. J. Bone Miner. Res. 19: 947-958.

Evron, E., Umbricht, C.B., Korz, D., Raman, V., Loeb, D.M., Niranjan, B., Buluwela, L., Weitzman, S.A., Marks, J., and Sukumar, S. 2001. Loss of cyclin D2 expression in the ma- 
jority of breast cancers is associated with promoter hypermethylation. Cancer Res. 61: 2782-2787.

Fackler, M.J., McVeigh, M., Evron, E., Garrett, E., Mehrotra, J., Polyak, K., Sukumar, S., and Argani, P. 2003. DNA methylation of RASSF1A, HIN-1, RAR- $\beta$, Cyclin D2 and Twist in in situ and invasive lobular breast carcinoma. Int. J. Cancer 107: 970-975.

Fauvarque, M.O., Zuber, V., and Dura, J.M. 1995. Regulation of polyhomeotic transcription may involve local changes in chromatin activity in Drosophila. Mech. Dev. 52: 343-355.

Fisher, A.G. 2002. Cellular identity and lineage choice. Nat. Rev. Immunol. 2: 977-982.

Fukami, T., Fukuhara, H., Kuramochi, M., Maruyama, T., Isogai, K., Sakamoto, M., Takamoto, S., and Murakami, Y. 2003. Promoter methylation of the TSLC1 gene in advanced lung tumors and various cancer cell lines. Int. J. Cancer 107: 53-59.

Ge, K., Guermah, M., Yuan, C.X., Ito, M., Wallberg, A.E., Spiegelman, B.M., and Roeder, R.G. 2002. Transcription coactivator TRAP220 is required for PPAR $\gamma 2$-stimulated adipogenesis. Nature 417: 563-567.

Grinberg, I. and Millen, K.J. 2005. The ZIC gene family in development and disease. Clin. Genet. 67: 290-296.

Hagihara, A., Miyamoto, K., Furuta, J., Hiraoka, N., Wakazono, K., Seki, S., Fukushima, S., Tsao, M.S., Sugimura, T., and Ushijima, T. 2004. Identification of $275^{\prime} \mathrm{CpG}$ islands aberrantly methylated and 13 genes silenced in human pancreatic cancers. Oncogene 23: 8705-8710.

Henrique, R., Jeronimo, C., Hoque, M.O., Nomoto, S., Carvalho, A.L., Costa, V.L., Oliveira, J., Teixeira, M.R., Lopes, C., and Sidransky, D. 2005. MT1G hypermethylation is associated with higher tumor stage in prostate cancer. Cancer Epidemiol. Biomarkers Prev. 14: 1274-1278.

Hernandez-Munoz, I., Taghavi, P., Kuijl, C., Neefjes, J., and van Lohuizen, M. 2005. Association of BMI1 with Polycomb bodies is dynamic and requires PRC2/EZH2 and the maintenance DNA methyltransferase DNMT1. Mol. Cell. Biol. 25: $11047-11058$.

Houldsworth, J., Heath, S.C., Bosl, G.J., Studer, L., and Chaganti, R.S. 2002. Expression profiling of lineage differentiation in pluripotential human embryonal carcinoma cells. Cell Growth Differ. 13: 257-264.

Hsieh, J. and Gage, F.H. 2004. Epigenetic control of neural stem cell fate. Curr. Opin. Genet. Dev. 14: 461-469.

Jaenisch, R. and Bird, A. 2003. Epigenetic regulation of gene expression: How the genome integrates intrinsic and environmental signals. Nat. Genet. 33 (Suppl.): 245-254.

Jenuwein, T. and Allis, C.D. 2001. Translating the histone code. Science 293: 1074-1080.

Kamminga, L.M., Bystrykh, L.V., de Boer, A., Houwer, S., Douma, J., Weersing, E., Dontje, B., and de Haan, G. 2005. The Polycomb group gene Ezh2 prevents hematopoietic stem cell exhaustion. Blood 107: 2170-2179.

Kassem, M. 2004. Mesenchymal stem cells: Biological characteristics and potential clinical applications. Cloning Stem Cells 6: 369-374.

Kirmizis, A., Bartley, S.M., Kuzmichev, A., Margueron, R., Reinberg, D., Green, R., and Farnham, P.J. 2004. Silencing of human polycomb target genes is associated with methylation of histone H3 Lys 27. Genes \& Dev. 18: 1592-1605.

Kluppel, M., Wight, T.N., Chan, C., Hinek, A., and Wrana, J.L. 2005. Maintenance of chondroitin sulfation balance by chondroitin-4-sulfotransferase 1 is required for chondrocyte development and growth factor signaling during cartilage morphogenesis. Development 132: 3989-4003.

Kugimiya, F., Kawaguchi, H., Kamekura, S., Chikuda, H., Ohba,
S., Yano, F., Ogata, N., Katagiri, T., Harada, Y., Azuma, Y., et al. 2005. Involvement of endogenous bone morphogenetic protein (BMP) 2 and BMP6 in bone formation. J. Biol. Chem. 280: 35704-35712.

Kuzmichev, A., Jenuwein, T., Tempst, P., and Reinberg, D. 2004. Different EZH2-containing complexes target methylation of histone $\mathrm{H} 1$ or nucleosomal histone H3. Mol. Cell 14: 183-193.

Lee, V.M. and Andrews, P.W. 1986. Differentiation of NTERA-2 clonal human embryonal carcinoma cells into neurons involves the induction of all three neurofilament proteins. $J$. Neurosci. 6: 514-521.

Lee, S.K., Lee, B., Ruiz, E.C., and Pfaff, S.L. 2005. Olig2 and Ngn2 function in opposition to modulate gene expression in motor neuron progenitor cells. Genes \& Dev. 19: 282-294.

Lengner, C.J., Lepper, C., van Wijnen, A.J., Stein, J.L., Stein, G.S., and Lian, J.B. 2004. Primary mouse embryonic fibroblasts: A model of mesenchymal cartilage formation. J. Cell. Physiol. 200: 327-333.

Lessard, J. and Sauvageau, G. 2003. Bmi-1 determines the proliferative capacity of normal and leukaemic stem cells. $\mathrm{Na}$ ture 423: 255-260.

Leung, C., Lingbeek, M., Shakhova, O., Liu, J., Tanger, E., Saremaslani, P., Van Lohuizen, M., and Marino, S. 2004. Bmil is essential for cerebellar development and is overexpressed in human medulloblastomas. Nature 428: 337-341.

Levine, S.S., King, I.F., and Kingston, R.E. 2004. Division of labor in Polycomb group repression. Trends Biochem. Sci. 29: 478-485.

Lewis, C.M., Cler, L.R., Bu, D.W., Zochbauer-Muller, S., Milchgrub, S., Naftalis, E.Z., Leitch, A.M., Minna, J.D., and Euhus, D.M. 2005. Promoter hypermethylation in benign breast epithelium in relation to predicted breast cancer risk. Clin. Cancer Res. 11: 166-172.

Li, X., Liu, P., Liu, W., Maye, P., Zhang, J., Zhang, Y., Hurley, M., Guo, C., Boskey, A., Sun, L., et al. 2005. Dkk2 has a role in terminal osteoblast differentiation and mineralized matrix formation. Nat. Genet. 37: 945-952.

Loeb, D.M., Evron, E., Patel, C.B., Sharma, P.M., Niranjan, B., Buluwela, L., Weitzman, S.A., Korz, D., and Sukumar, S. 2001. Wilms' tumor suppressor gene (WT1) is expressed in primary breast tumors despite tumor-specific promoter methylation. Cancer Res. 61: 921-925.

Lund, A.H. and van Lohuizen, M. 2004. Polycomb complexes and silencing mechanisms. Curr. Opin. Cell Biol. 16: 239246.

Ma, Q., Kintner, C., and Anderson, D.J. 1996. Identification of neurogenin, a vertebrate neuronal determination gene. Cell 87: 43-52.

Molofsky, A.V., Pardal, R., Iwashita, T., Park, I.K., Clarke, M.F., and Morrison, S.J. 2003. Bmi-1 dependence distinguishes neural stem cell self-renewal from progenitor proliferation. Nature 425: 962-967.

Molofsky, A.V., Pardal, R., and Morrison, S.J. 2004. Diverse mechanisms regulate stem cell self-renewal. Curr. Opin. Cell Biol. 16: 700-707.

Niederreither, K., Vermot, J., Schuhbaur, B., Chambon, P., and Dolle, P. 2000. Retinoic acid synthesis and hindbrain patterning in the mouse embryo. Development 127: 75-85.

Orlando, V. 2003. Polycomb, epigenomes, and control of cell identity. Cell 112: 599-606.

Orlando, V., Jane, E.P., Chinwalla, V., Harte, P.J., and Paro, R. 1998. Binding of trithorax and Polycomb proteins to the bithorax complex: Dynamic changes during early Drosophila embryogenesis. EMBO J. 17: 5141-5150.

Pasini, D., Bracken, A.P., and Helin, K. 2004a. Polycomb group 
Bracken et al.

proteins in cell cycle progression and cancer. Cell Cycle 3: 396-400.

Pasini, D., Bracken, A.P., Jensen, M.R., Lazzerini Denchi, E., and Helin, K. 2004b. Suz12 is essential for mouse development and for EZH2 histone methyltransferase activity. EMBO J. 23: 4061-4071.

Pearson, J.C., Lemons, D., and McGinnis, W. 2005. Modulating Hox gene functions during animal body patterning. Nat. Rev. Genet. 6: 893-904.

Pirrotta, V. and Gross, D.S. 2005. Epigenetic silencing mechanisms in budding yeast and fruit fly: Different paths, same destinations. Mol. Cell 18: 395-398.

Raaphorst, F.M. 2005. Deregulated expression of Polycombgroup oncogenes in human malignant lymphomas and epithelial tumors. Hum. Mol. Genet. 14: R93-R100.

Rastelli, L., Chan, C.S., and Pirrotta, V. 1993. Related chromosome binding sites for zeste, suppressors of zeste and Polycomb group proteins in Drosophila and their dependence on Enhancer of zeste function. EMBO J. 12: 1513-1522.

Ren, B., Robert, F., Wyrick, J.J., Aparicio, O., Jennings, E.G., Simon, I., Zeitlinger, J., Schreiber, J., Hannett, N., Kanin, E., et al. 2000. Genome-wide location and function of DNA binding proteins. Science 290: 2306-2309.

Reya, T., Morrison, S.J., Clarke, M.F., and Weissman, I.L. 2001. Stem cells, cancer, and cancer stem cells. Nature 414: 105111 .

Ringrose, L. and Paro, R. 2004. Epigenetic regulation of cellular memory by the Polycomb and Trithorax group proteins. Annu. Rev. Genet. 38: 413-443.

Ringrose, L., Ehret, H., and Paro, R. 2004. Distinct contributions of histone H3 lysine 9 and 27 methylation to locus-specific stability of Polycomb complexes. Mol. Cell 16: 641-653.

Rohwedel, J., Maltsev, V., Bober, E., Arnold, H.H., Hescheler, J., and Wobus, A.M. 1994. Muscle cell differentiation of embryonic stem cells reflects myogenesis in vivo: Developmentally regulated expression of myogenic determination genes and functional expression of ionic currents. Dev. Biol. 164: $87-101$.

Sato, T., Sasai, N., and Sasai, Y. 2005. Neural crest determination by co-activation of Pax3 and Zic1 genes in Xenopus ectoderm. Development 132: 2355-2363.

Shackleton, M., Vaillant, F., Simpson, K.J., Stingl, J., Smyth, G.K., Asselin-Labat, M.L., Wu, L., Lindeman, G.J., and Visvader, J.E. 2006. Generation of a functional mammary gland from a single stem cell. Nature 439: 84-88.

Simeone, A., Acampora, D., Arcioni, L., Andrews, P.W., Boncinelli, E., and Mavilio, F. 1990. Sequential activation of HOX2 homeobox genes by retinoic acid in human embryonal carcinoma cells. Nature 346: 763-766.

Valk-Lingbeek, M.E., Bruggeman, S.W., and van Lohuizen, M. 2004. Stem cells and cancer; the Polycomb connection. Cell 118: 409-418.

Vire, E., Brenner, C., Deplus, R., Blanchon, L., Fraga, M., Didelot, C., Morey, L., Van Eynde, A., Bernard, D., Vanderwinden, J.M., et al. 2005. The Polycomb group protein EZH2 directly controls DNA methylation. Nature 439: 871-874.

Wang, J., Elghazi, L., Parker, S.E., Kizilocak, H., Asano, M., Sussel, L., and Sosa-Pineda, B. 2004. The concerted activities of Pax4 and Nkx2.2 are essential to initiate pancreatic $\beta$-cell differentiation. Dev. Biol. 266: 178-189.

Zandbergen, F., Mandard, S., Escher, P., Tan, N.S., Patsouris, D., Jatkoe, T., Rojas-Caro, S., Madore, S., Wahli, W., Tafuri, S., et al. 2005. The G0/G1 switch gene 2 is a novel PPAR target gene. Biochem. J. 392: 313-324.

Zhao, W., Hisamuddin, I.M., Nandan, M.O., Babbin, B.A.,
Lamb, N.E., and Yang, V.W. 2004. Identification of Kruppellike factor 4 as a potential tumor suppressor gene in colorectal cancer. Oncogene 23: 395-402.

Zhu, Q., Couillard-Despres, S., and Julien, J.P. 1997. Delayed maturation of regenerating myelinated axons in mice lacking neurofilaments. Exp. Neurol. 148: 299-316. 


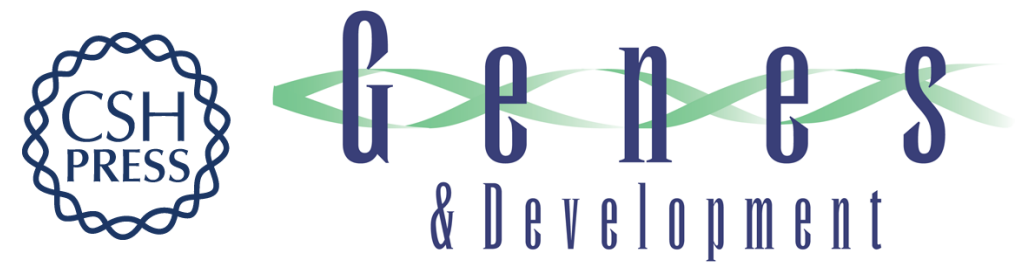

\section{Genome-wide mapping of Polycomb target genes unravels their roles in cell fate transitions}

Adrian P. Bracken, Nikolaj Dietrich, Diego Pasini, et al.

Genes Dev. 2006, 20:

Access the most recent version at doi:10.1101/gad.381706

\section{Supplemental http://genesdev.cshlp.org/content/suppl/2006/04/17/gad.381706.DC1 Material}

References This article cites 66 articles, 22 of which can be accessed free at: http://genesdev.cshlp.org/content/20/9/1123.full.html\#ref-list-1

\section{License}

Email Alerting

Receive free email alerts when new articles cite this article - sign up in the box at the top Service 